\title{
Rodoviário, ferroviário ou marítimo de cabotagem? O uso da técnica de preferência declarada para avaliar a intermodalidade no Brasil
}

\author{
Antônio Galvão Novaes'; Brunno Santos Gonçalves²; \\ Maria Beatriz Costa ${ }^{3}$; Silvio dos Santos ${ }^{4}$
}

\begin{abstract}
Resumo: A modelagem da demanda de transporte de carga no Brasil ainda é pouco difundida, principalmente devido às dificuldades para obtenção de dados acerca do setor. A utilização da Técnica de Preferência Declarada vem consolidando-se como uma ferramenta bastante eficiente para a coleta de dados e posterior utilização em modelos de divisão modal e alocação de demanda. Neste estudo, elaborou-se a partir da Técnica de Preferência Declarada uma metodologia para a modelagem da demanda de cargas de alto valor agregado brasileiras, buscando verificar na opinião de embarcadores, qual a importância relativa de determinados fatores, tais como, tarifa, confiabilidade, tempo, intervalo entre embarques e segurança, quando da escolha dos modos de transporte, rodoviário, ferroviário ou marítimo de cabotagem.
\end{abstract}

\begin{abstract}
The modeling of cargo transport demand in Brazil is still incipient, mainly due the difficulty of getting data on such a sector of the economy. The use of Stated Choice experiments has proved to be an efficient method to gather data and treat them in association with modal split and demand allocation models. In this study, a method of modeling the Brazilian transport demand of high addedvalue products, based on Stated Choice Techniques, was developed. The objective is to gather the opinion of shippers regarding the relative importance of a set of factors, such as tariff, confidence, lead-time, interval between dispatchs and safety, all of them related to the choice of the transport mode (road, railroad or coastwise navigation).
\end{abstract}

\section{INTRODUÇÃO}

O setor de transportes de carga brasileiro atravessa um período um tanto quanto paradoxal. Se, por um lado, em virtude dos processos de privatização, houve a revitalização parcial dos sistemas ferroviário e portuário, por outro, as carências inerentes à infra-estrutura de transporte ainda são significativas, e aumentam proporcionalmente ao crescimento econômico, tornando-se um entrave à distribuição eficiente de produtos no mercado interno e à competitividade do país no mercado externo. Existem, nesse setor, boas possibilidades para aumento da produtividade e da qualidade dos serviços logísticos, investimentos e novas políticas socioeconômicas.

O planejamento de uma matriz de transportes mais eficiente e a mobilização pública e privada para a efetivação dessa diretriz podem representar o rompimento de antigos paradigmas políticos e a efetivação de um novo ciclo de desenvolvimento para a nação brasi-

\footnotetext{
${ }^{1}$ Antônio Galvão Novaes, Laboratório de Transportes, Universidade Federal de Santa Catarina. Florianópolis, SC, Brasil. (e-mail novaes@deps.ufsc.br).

${ }^{2}$ Brunno Santos Gonçalves, Laboratório de Transportes, Universidade Federal de Santa Catarina. Florianópolis, SC, Brasil. (e-mail: sgbrunno@hotmail.com).

${ }^{3}$ Maria Beatriz Costa, Laboratório de Transportes, Universidade Federal de Santa Catarina. Florianópolis, SC, Brasil. (e-mail: beabcosta@gmail.com).

${ }^{4}$ Silvio dos Santos, Laboratório de Transportes, Universidade Federal de Santa Catarina. Florianópolis, SC, Brasil. (e-mail: silviodosantos@terra.com.br).
}

Este artigo é parte de TRANSPORTES, volume XIV, número 2, dezembro de 2006. ISSN: 1415-7713. leira.

Sendo a ferrovia e a cabotagem modos de transporte com menor custo do que a rodovia, mudanças na matriz brasileira fariam com que as mercadorias chegassem às prateleiras com custo menor, podendo atingir, assim, preços menores de venda. Com preços menores, o poder aquisitivo da população, dado pela sua renda disponível, subiria sem qualquer aumento salarial, permitindo a compra de mais unidades. A conseqüência disso seria direta. Com mais consumo haveria mais compras pelos distribuidores, o que implicaria no aumento da produção. $\mathrm{O}$ resultado seria observado na forma de maiores investimentos no aparelho produtivo e no aumento de emprego, gerando mais renda disponível na economia. Estaria estabelecido, pelo menos parcialmente, o chamado círculo virtuoso da economia (ANTT-UFSC, 2003).

A modelagem da demanda por transporte, de carga ou passageiros, é poderosa ferramenta de auxilio ao planejamento dos sistemas de transportes e processos de tomadas de decisões. A identificação detalhada da demanda por transportes permite que se busquem soluções adequadas para atender suas características específicas, possibilitando avaliar o impacto da implantação de novas tecnologias e serviços.

Apesar da grande variedade de abordagens no processo de desenvolvimento de modelos, existe um consenso de que a modelagem, no setor de transporte de carga, é bem menos desenvolvida do que no caso do transporte de passageiros, especialmente na esfera urbana (Ortúzar e Willumsen, 1994). 
Neste estudo apresentaremos uma contribuição à modelagem de transportes de carga, através da analise da estrutura de decisão dos usuários de transporte de carga geral no Brasil, avaliando quais os fatores relevantes para a escolha dos modos de transportes rodoviários, ferroviários e de cabotagem. Para tanto, entrevistas com embarcadores, transportadores e especialistas do setor foram realizadas, utilizando questionários elaborados segundo a técnica de Preferência Declarada.

O artigo começa com um apanhado geral da situação atual da infra-estrutura de transportes rodoviária, ferroviária e de cabotagem brasileira. Em seguida apresenta-se a fundamentação teórica utilizada, o desenvolvimento metodológico, os resultados obtidos e, posteriormente, as principais conclusões e recomendações.

\section{INFRA-ESTRUTURA DE TRANSPORTES BRASILEIRA: MODOS RODOVIÁRIO, FERROVIÁRIO E MARÍTIMO DE CABOTAGEM}

No Brasil, a distribuição interna de produtos é bastante dependente do modo rodoviário. Cerca de $66 \%$ da carga é movimentada pelo modo rodoviário, $21 \%$ pelo ferroviário e $13 \%$ via cabotagem, sendo que a intermodalidade é mais intensa para o transporte de produtos de baixo valor agregado, tais como minério de ferro, grãos e cimento. A dependência do modo rodoviário é ainda maior quando se analisam apenas produtos de alto valor agregado, pois para estes, $87 \%$ da carga é transportada pelo modo rodoviário, o que mostra que tanto a ferrovia como a cabotagem ainda apresentam poucas condições para o transporte desses produtos.

Apesar dessa grande dependência, atualmente o estado de conservação das rodovias brasileiras é bastante precário. Pesquisas apontam que $83 \%$ das rodovias, apresentam o estado de conservação deficiente, ruim ou péssimo. Outro problema é a regulamentação do setor, a qual se encontra distante dos padrões desejáveis. A falta de disciplina no transporte rodoviário de cargas no Brasil permite o funcionamento de transportadoras sem condições econômicas de exercício da atividade, bem como a circulação de caminhões sucateados (idade média da frota: 18 anos), com sobrepeso e a existência de jornadas de trabalho excessivas, colocando em risco a mercadoria e o trabalhador.

O setor ferroviário nacional passou por uma revitalização com o programa de privatização que teve como marco fundamental a Lei das Concessões de 1995. Passou-se a adotar um modelo no qual a empresa concessionária responsabiliza-se pela manutenção da infra-estrutura, operação, controle de tráfego, marketing e finanças da malha, por um período de arrendamento de 30 anos e o governo, através da ANTT (Agência
Nacional de Transportes Terrestres), estabelece metas referentes à segurança, desempenho operacional e ao respeito ao meio ambiente.

Outro aspecto a ser considerado, e talvez o principal desafio do setor, é a integração intra e intermodal da malha ferroviária. Problemas como os diferentes tipos de bitola, transposição de áreas urbanas, direitos de passagem entre concessionárias, pouca oferta de terminais de integração intermodal, entre outros, inviabilizam o uso mais intenso das ferrovias brasileiras em longas distâncias, quando estas se tornam mais competitivas.

Além disso, a oferta de vagões ferroviários ainda é insuficiente, situação que é agravada pelas baixas velocidades desenvolvidas ao longo de boa parte da malha brasileira, o que leva a uma subutilização da já restrita frota ferroviária, devido aos longos ciclos de viagem decorrentes das distâncias a percorrer.

Num país que apresenta 7.408 quilômetros de extensão de costa, em que as principais cidades, os pólos industriais e os centros consumidores concentram-se no litoral ou próximo a ele, o segmento de cabotagem apresenta-se como alternativa viável para compor a cadeia de suprimentos de diversos setores, e já começa as ser utilizada pelas indústrias de higiene e limpeza, eletroeletrônica e automotiva. No entanto a oferta de navios ainda é pequena e pouco explorada.

Após a implantação da Lei de Modernização dos Portos em 1993, o setor portuário nacional ainda vivencia um período de transformação, com claros sinais de melhoria das condições das operações, níveis de serviço e custos. No entanto, outras ações que visem ao aumento da eficiência das operações portuárias - sejam melhoria e adequação dos acessos ferroviários, rodoviário e marítimo; seja o aumento da oferta de navios ou a revitalização do setor de construção naval - favoreceriam a competitividade logística do setor e do país.

\section{MODELAGEM: FUNDAMENTAÇÃO TEÓRICA}

De acordo com Novaes (1986), quando se utiliza o termo modelo, não se está empregando apenas o significado matemático ou computacional, mas o utilizando no sentido de obter um enfoque definido e consistente da realidade, um quadro bem estruturado que possa ser justificado com o apoio de alguma teoria ou de princípios técnico-econômicos universalmente aceitos.

A modelagem e o ferramental a serem desenvolvidos nesse estudo têm, como principal subsídio para análise, o modelo comportamental desagregado do tipo Logit Multinomial, o qual se encontra descrito a seguir. Para o delineamento desse tipo de modelo comportamental é necessário, em primeiro lugar, me- 
dir quantitativamente as preferências dos usuários, medida esta baseada no conceito de utilidade e formalizada através de uma função utilidade.

O uso da utilidade para medir a satisfação que um consumidor extrai de um bem ou serviço advém da Teoria Clássica do Consumidor. Para Ferguson (1994), a principal hipótese sobre a qual a teoria do comportamento do consumidor e da demanda está construída, é que o consumidor procura alocar sua renda monetária (limitada) entre bens e serviços, de tal forma a maximizar sua satisfação.

A função utilidade normalmente assume a forma de modelos aditivos compensatórios, já que se pode melhorar um atributo piorando outro, e assim manter o mesmo nível de utilidade. Esta função apresenta a seguinte configuração geral:

$$
U=a_{1} \cdot X_{1}+a_{2} \cdot X_{2}+\ldots+a_{n} \cdot X_{n}
$$

em que,

$$
\begin{array}{ll}
U: & \text { medida de utilidade; } \\
X_{n}: & \text { atributos do produto ou serviço e } \\
a_{n}: & \text { coeficientes do modelo. }
\end{array}
$$

Os coeficientes do modelo $\left(a_{1}, a_{2}, \ldots, a_{n}\right)$ podem ser utilizados para várias finalidades, entre elas para determinar o peso relativo de cada atributo incluído no modelo, e para especificar a probabilidade de escolha de cada alternativa nos modelos de previsão de demanda.

Assim, a partir da utilização de técnicas de Preferência Declarada e da calibração de uma função utilidade, obtém-se a base de dados necessária para utilização de Modelo Logit Multinomial, que tem a seguinte formulação:

$$
P_{i}=\frac{e^{U_{i}}}{\sum_{j=1}^{n} e^{U_{j}}}
$$

em que,

$P_{i}$ : $\quad$ probabilidade da alternativa $i$ ser escolhida;

$e: \quad$ número de Neper (2,78182);

$j$ : $\quad$ alternativas consideradas e

$U_{j}$ : utilidades das alternativas consideradas.

\section{METODOLOGIA: ESTUDO APLICADO}

O modelo a ser desenvolvido a partir da Técnica de Preferência Declarada tem como objetivo a avaliação de possíveis alterações na matriz de transporte de produtos de alto valor agregado brasileira, os quais foram considerados como todos aqueles produtos que sofrem processos de industrialização de forma a elevar seu valor unitário, tais como: couros, calçados, tintas, plásticos, roupas e tecidos, cerâmica, produtos eletromecânicos, produtos eletro-eletrônicos, produtos siderúrgicos, sucos, alimentos industrializados, produtos de higiene e limpeza.

A seleção dos atributos baseou-se nos trabalhos publicados por Effron e Rose (2002), Senna e Stanton (2002), e nas principais dificuldades apontados por embarcadores, associações e transportadores para o escoamento de suas mercadorias em um levantamento feito no estudo "Logística e Transporte para Produtos de Alto Valor Agregado no Contexto Brasileiro" (ANTT-UFSC, 2003). Por estar se analisando nesse estudo um sistema logístico extremamente complexo e heterogêneo, partiu-se da idéia de montar um experimento mais abrangente no qual se utilizariam atributos gerais, fundamentais à prestação de qualquer serviço logístico, independentemente do tipo de carga geral embarcada (mais alto ou mais baixo valor agregado), nível de atividade na cadeia logística ou mercado (embarcador, transportador, especialista) ou rota a ser transportada.

Foi observado que entre os modos de transportes realizados já existia um nível de variação considerável entre determinados atributos. Assim, optou-se por oferecer variações somente nos atributos mais relevantes de cada modo na montagem do experimento, reduzindo assim, o número total de combinações, e facilitando o delineamento do experimento. O Quadro 1 apresenta os atributos escolhidos e seus respectivos níveis de variação para cada um dos modos de transporte.

Realizou-se o delineamento do experimento para cada um dos modos separadamente, ou seja, o cálculo das alternativas possíveis e eventuais métodos de re-

\begin{tabular}{|c|c|c|c|c|}
\hline ATRIBUTO & DESCRIÇÁO & RODOVIÁRIO & FERROVIARIO & CABOTAGEM \\
\hline Frete & $\begin{array}{l}\text { Frete média do modo de transporte, desde a origem até o } \\
\text { destino (distância média de } 2000 \mathrm{~km} \text { ) }\end{array}$ & $\begin{array}{l}\text { 1. US } \$ 30,00 / 1000 \mathrm{tku} \\
\text { 2. US } \$ 25,00 / 1000 \mathrm{tku} \\
\text { 3. US } \$ 20,00 / 1000 \mathrm{tku}\end{array}$ & 1. US $\$ 20,00 / 1000 \mathrm{tku}$ & 1. US $\$ 10,00 / 1000 \mathrm{tku}$ \\
\hline Confiabilidade & Confiabilidade nos contratos e prazos firmados & 1. Confiável & $\begin{array}{l}\text { 1. Confiável } \\
\text { 2. Não Confiável }\end{array}$ & $\begin{array}{l}\text { 1. Confiável } \\
\text { 2. Não Confiável }\end{array}$ \\
\hline Tempo & $\begin{array}{l}\text { Tempo porta a porta, desde a coleta da mercadoria na } \\
\text { fábrica até o destino final }\end{array}$ & 1. 3 dias & $\begin{array}{l}\text { 1. } 5 \text { dias } \\
\text { 2. } 7 \text { dias }\end{array}$ & $\begin{array}{l}\text { 1. } 5 \text { dias } \\
\text { 2. } 8 \text { dias }\end{array}$ \\
\hline Intervalo & $\begin{array}{l}\text { Intervalo para a disponibilidade do modo de transporte } \\
\text { entre embarques sucessivos }\end{array}$ & 1. Diária & $\begin{array}{l}\text { 1. de } 3 \text { em } 3 \text { dias } \\
\text { 2. Semanal }\end{array}$ & $\begin{array}{l}\text { 1. Semanal } \\
\text { 2. Quinzenal }\end{array}$ \\
\hline Segurança & Risco de Roubo de Carga & $\begin{array}{l}\text { 1. Insignificante } \\
\text { 2. Significante }\end{array}$ & 1. Insignificante & 1. Insignificante \\
\hline
\end{tabular}
dução do experimento foram realizados de forma isolada, resultando em um número específico de alternativas ou cenários para cada modo de transporte.

Quadro 1: Atributos delineados na pesquisa de Preferência Declarada e Níveis dos Atributos 
Para o modo rodoviário, os atributos confiabilidade, tempo e freqüência foram mantidos fixos, os atributos tarifa, com 3 níveis e os de segurança, com 2 níveis, gerando 6 alternativas. No caso do ferroviário e do marítimo de cabotagem, os atributos tarifa e segurança foram mantidos fixos, enquanto que para os atributos confiabilidade, tempo e freqüência foram estabelecidos 2 níveis para cada um, gerando 8 alternativas possíveis para cada modo de transporte. Estas foram reduzidas para quatro, por intermédio da técnica de fatorial fracionário, restando, finalmente, 4 alternativas possíveis para cada modalidade.

As seis alternativas possíveis geradas para o modo rodoviário, combinadas aleatoriamente com as quatro alternativas do ferroviário e as quatro alternativas da cabotagem, geraram 96 tipos de cartões de escolhas, cada um compondo um cenário alternativo para cada modalidade de transporte.

Optou-se por realizar um experimento do tipo Choice, ou seja, em um bloco com três alternativas de transporte que seria apresentado ao entrevistado, que optaria por apenas uma. Desta forma, subdividiram-se os 96 blocos contendo os três modos de transporte em 8 grupos de 12 blocos por entrevista. Assim para ter amostragem estatística suficiente para tentar calibrar o modelo, 96 escolhas teriam que ser feitas, de modo que, com 8 entrevistas completas validadas, obter-seia um experimento completo.

A coleta de dados foi realizada através de entrevistas realizadas em Seminário de Pesquisa organizado pelo Laboratório de Transporte da UFSC, como parte do estudo "Logística e Transportes para Produtos de Alto Valor Agregado no Contexto Brasileiro”. Nesse encontro estavam presentes representantes de diversos setores produtivos, transportadores rodoviários, ferroviários e marítimos, especialistas e membros do governo federal, discutindo as dificuldades, necessidades e potencialidades inerentes ao atual cenário logístico brasileiro.

No total foram realizadas 16 entrevistas, o que gerou 192 escolhas, ou seja, dois experimentos completos foram respondidos, o que foi suficiente para rodar e testar uma primeira calibração do modelo.

\section{RESULTADOS}

\subsection{Calibração da função utilidade}

O Quadro 2 mostra os resultados obtidos a partir da pesquisa de preferência declarada realizada. As estimativas dos parâmetros ou coeficientes do modelo foram obtidas usando o software Alogit. Vale ressaltar que toda a amostragem - 16 entrevistas e 192 escolhas - foi considerada.

Em uma primeira análise, verificou-se que os sinais dos coeficientes foram condizentes com o esperado,
Quadro 2: Resultados obtidos

\begin{tabular}{|l|c|c|}
\hline \multicolumn{1}{|c|}{ ATRIBUTOS } & $\boldsymbol{\beta}$ & $\mathbf{t}$-student \\
\hline Tarifa & $-0,0874$ & $-4,6$ \\
Confiabilidade & 1,9590 & 6,7 \\
Tempo & $-0,3185$ & $-3,5$ \\
Intervalo & $-0,0837$ & $-2,3$ \\
Segurança (Risco) & $-0,8335$ & 2,7 \\
\hline Outras Estatística: & \\
Número de Entrevistas: 16 & \\
Número de Escolhas: 192 & \\
"Rho - Squared": 0,2433 & \\
\hline
\end{tabular}

ou seja:

- Atributos diretamente proporcionais à utilidade (sinal positivo): Confiabilidade;

- Atributos inversamente proporcionais à utilidade (sinal negativo): Tarifa, Tempo, Intervalo, Risco.

Os valores obtidos para o teste t-Student mostraram que todos os coeficientes beta dos atributos foram significativos a um nível de significância de 0,005 (99\% de confiança), exceto o atributo Intervalo entre embarques, cujo valor de beta possui um nível de significância de 0,01 (98\% de confiança). Além disso, notase que o atributo confiabilidade seguido pelo atributo tarifa, são os atributos que apresentaram maior peso na opinião dos entrevistados, haja vista que apresentaram os maiores valores absolutos de t-Student.

Outra estatística importante é o Rho quadrado que apresentou o valor de 0,2433 , dentro portanto do intervalo aceitável que compreende valores entre 0,2 e 0,4 .

Assim, considerou-se calibrada estatisticamente a seguinte função utilidade:

$$
\begin{aligned}
U_{i}= & -0,0874 \cdot \operatorname{Tr}_{i}+1,9559 \cdot C_{i}-0,3185 \cdot T_{i} \ldots \\
& \ldots-0,0837 \cdot I_{i}-0,8335 \cdot S_{i}
\end{aligned}
$$

em que,

$U_{i}: \quad$ utilidade do modo $i$;

$\operatorname{Tr}_{i}: \quad$ tarifa do modo $i$;

$C_{i}$ : $\quad$ confiabilidade do modo $i$;

$T_{i}$ : tempo gasto desde a coleta à entrega utilizando o modo $i$;

$I_{i}$ : $\quad$ intervalo entre embarques para o modo $i$;

$S_{j}: \quad$ segurança do modo $i$.

\subsection{Aplicação do modelo Logit Multinomial}

Para atestar a aplicabilidade da função utilidade calibrada, aplicou-se o modelo Logit Multinomial, considerando - para cada um dos modos de transportes e seus respectivos atributos - valores médios condizentes com a realidade brasileira, conforme mostra o Quadro 3.

Para este cenário padrão, aplicando-se o Modelo Logit Multinomial calibrado (LMN), obtiveram-se valores de divisão modal bem próximos à realidade encontrada no estudo realizado na pesquisa da ANTTUFSC (2003), conforme pode ser constatado no Qua- 
Tabela 3: Cenário padrão: Valores utilizados

\begin{tabular}{|c|c|c|c|c|c|}
\hline Modal & Tarifa & Confiabilidade & Tempo & Intervalo & Segurança (Risco) \\
\hline Rodoviário & US\$ 45,00 por mil tku & Confiável & 3 dias & 1 em 1 dia & Médio \\
\hline Ferroviário & US\$ 32,00 por mil tku & Pouco Confiável & 8 dias & 3 em 3 dias & Baixo \\
\hline Cabotagem & US\$ 26,00 por mil tku & Pouco Confiável & 10 dias & 7 em 7 dias & Baixo \\
\hline
\end{tabular}

Tabela 4: Comparação da divisão modal: ANTT-UFSC (2003) e LMN

\begin{tabular}{|l|c|c|}
\hline \multicolumn{1}{|c|}{ MODAL } & $\begin{array}{c}\text { ANTTIUFSC } \\
(2003)\end{array}$ & $\begin{array}{c}\text { MODELO } \\
\text { CALIBRADO }\end{array}$ \\
\hline Rodoviário & $87.0 \%$ & $84.2 \%$ \\
Ferroviário & $8.2 \%$ & $9.6 \%$ \\
Cabotagem & $4.5 \%$ & $6.2 \%$ \\
Aéreo & $0.3 \%$ & Não considerado \\
\hline
\end{tabular}

dro 4, o que atesta a boa fidedignidade do modelo.

\subsection{Análise de sensibilidade}

Finalmente, procedeu-se a análise de sensibilidade dos atributos da função utilidade calibrada, verificando a influência de cada um no nível de utilização dos diferentes modos de transporte. Para tal, fez-se uso do modelo Logit Multinomial, tendo como referência o cenário padrão apresentado no Quadro 3. Efetuaramse variações apenas nos valores do atributo e respectivo modo em análise, mantendo-se fixos os demais valores de atributos. Repetiu-se o mesmo procedimento para os demais atributos e modos, obtendo-se as curvas de elasticidade de cada um dos atributos, as quais são apresentadas a seguir.

Dentre os atributos considerados nesse modelo, segundo os entrevistados, a confiabilidade é o atributo de maior impacto para a escolha de determinado modo de transporte. Aumentos nos níveis de confiabilidade dos serviços oferecidos pelas alternativas ferroviárias e de cabotagem podem representar o aumento da participação desses modos na matriz de transporte de $8 \%$ para $25 \%$ no ferroviário, de $5 \%$ para $20 \%$ na cabotagem e de $60 \%$ para $90 \%$ no rodoviário. Vale ressaltar que a confiabilidade de uma operação de transporte advém do funcionamento conjunto e eficiente de uma série de fatores logísticos, tais como informação, e- quipamentos, infra-estrutura e qualificação da mãode-obra. A melhoria gradativa na prestação de serviço logístico certamente representará incrementos na confiabilidade do mesmo e o aumento da demanda captável do modo de transporte.

A tarifa mostrou-se um fator importante na escolha dos embarcadores, sendo que para o rodoviário a amplitude da variação é grande, entre $60 \%$ a $100 \%$. Nos outros modos (ferroviário e de cabotagem), apesar de sofrerem uma variação menor que o rodoviário, o aumento crescente da tarifa reduz a utilização dessas alternativas de transporte a níveis próximo de zero.

$\mathrm{O}$ atributo segurança tem pequena sensibilidade em todos os modos de transportes. Apesar de a segurança ser crítica no modo rodoviário, a variação de utilização, de acordo com os resultados do modelo, é pequena.

O atributo intervalo entre embarques sucessivos é menos sensível a variações do que os atributos confiabilidade e tarifa. Para o modo ferroviário, a variação do intervalo entre embarques sucessivos de uma freqüência semanal para uma freqüência diária pode representar o aumento da sua participação de $7 \%$ para 12\% Já na cabotagem, variações nas freqüências quinzenais para semanal aumentariam a participação de $2 \%$ para $4 \%$.

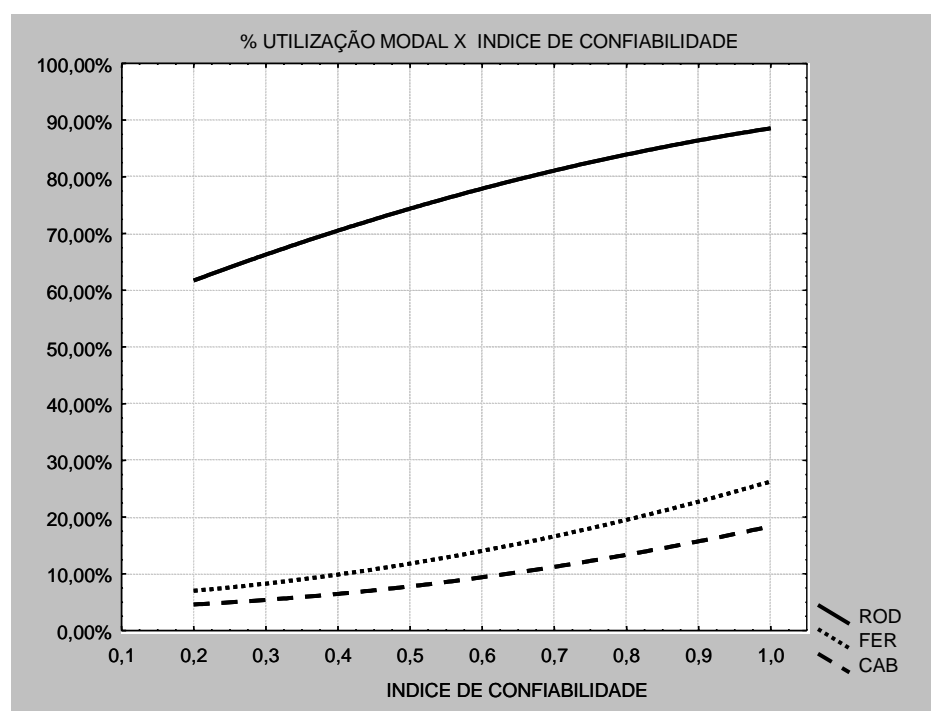

Figura 1: Analise de sensibilidade do atributo Confiabilidade 


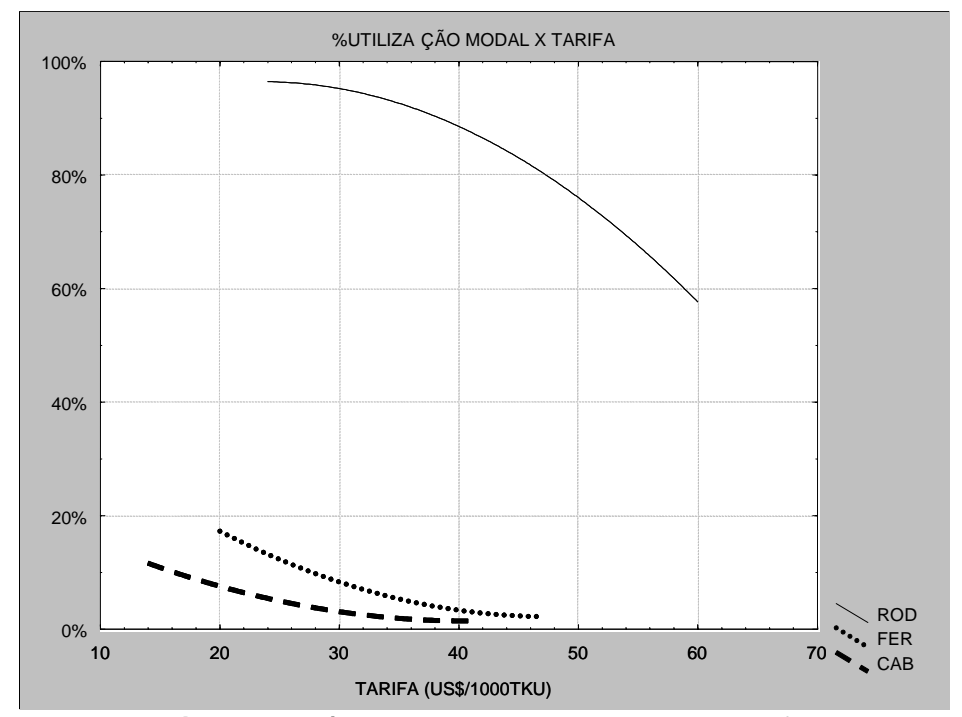

Figura 2: Análise de sensibilidade do atributo Tarifa

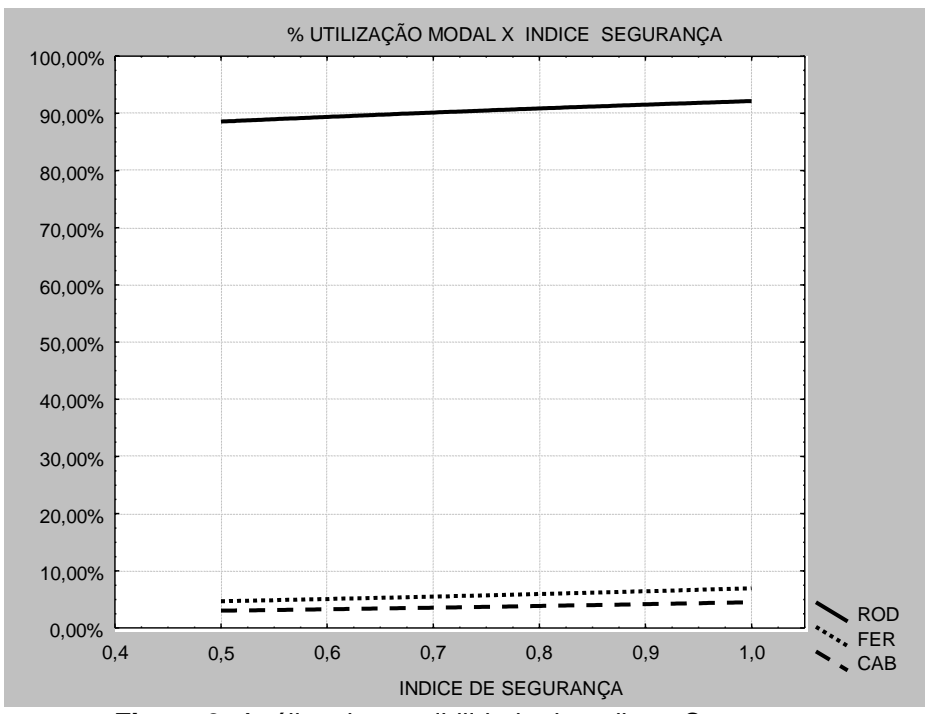

Figura 3: Análise de sensibilidade do atributo Segurança

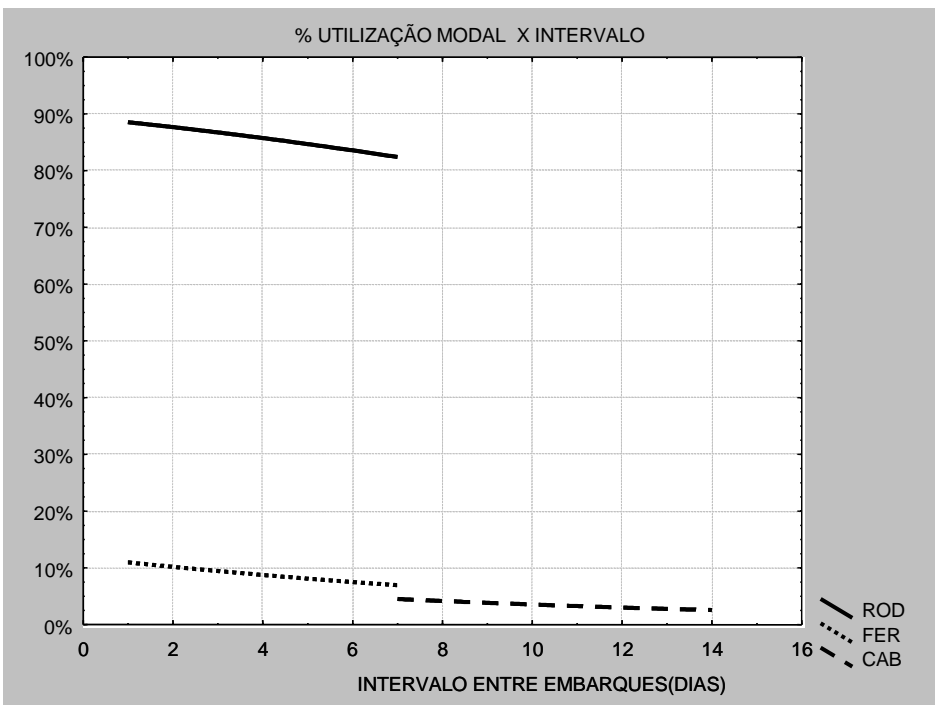

Figura 4: Análise de sensibilidade do atributo Intervalo

A variação do atributo tempo é mais rígida para a rodovia, pois seus clientes esperam sempre uma entrega rápida. É mais tolerável para a ferrovia e cabotagem. Além disso, reduções nos tempos de entrega das operações em que se utilizam os modos ferroviários e de cabotagem podem alterar substancialmente sua participação na matriz de transportes. 


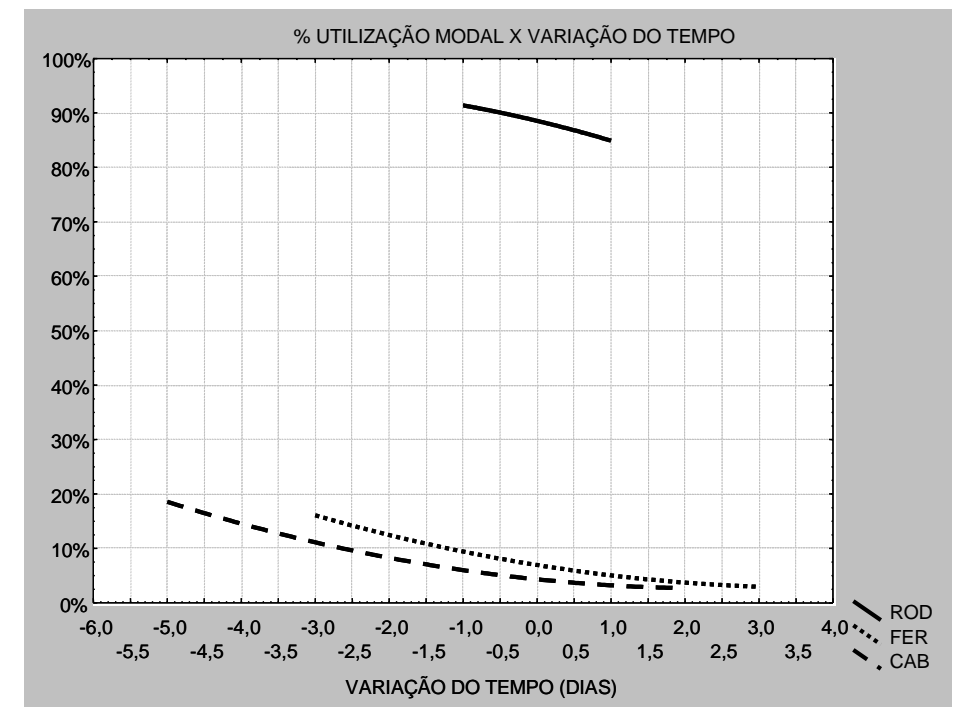

Figura 5: Analise de sensibilidade do atributo Tempo

\section{CONSIDERAÇÕES FINAIS}

Um dos objetivos desse estudo foi o delineamento uma metodologia utilizando a Técnica de Preferência Declarada que permite modelar a demanda de transportes de carga de alto valor agregado no Brasil.

A pesquisa de Preferência Declarada foi o alicerce principal para o desenvolvimento de todo o estudo, sendo fundamental para a obtenção de bons resultados o delineamento criterioso do experimento. As principais vantagens observadas quanto ao uso dessa técnica são o fato de que poucas entrevistas são necessárias para a obtenção de um modelo consistente e a possibilidade de compreender o conjunto de fatores ou padrões de comportamento que regem as tomadas de decisões dos usuários de transportes. Além disso, a possibilidade de mensurar variáveis qualitativas como confiabilidade, segurança, entre outras.

Dentre os atributos avaliados, apresentaram maior importância na opinião dos embarcadores a tarifa e a confiabilidade do modo de transporte. Na prática implica dizer que, para a concepção de futuros estudos de planejamento de sistemas de transportes para cenário brasileiro, é absolutamente necessário investigar a importância relativa das variáveis tarifa e confiabilidade do modo de transporte, bem como de seus efeitos sobre a demanda.

O modelo encontrado representa uma análise comportamental generalista dos embarcadores, com relação à escolha dos modos de transporte rodoviário, ferroviário e cabotagem. Para análise preliminar de investimentos, decisões políticas e regulamentações, por exemplo, podemos considerá-lo uma ferramenta útil. Para análises mais aprofundadas sugere-se a realização de pesquisa de preferência revelada o que possibilitaria ajustes mais precisos ao modelo e/ou pesquisas específicas para determinados produtos e/ou rota.

\section{AGRADECIMENTOS}

Os autores agradecem a toda equipe do Laboratório de Transportes da Universidade Federal de Santa Catarina e a todos aqueles que contribuíram direta ou indiretamente para a realização dessa pesquisa.

\section{REFERÊNCIAS BIBLIOGRÁFICAS}

ANTT-UFSC (2003) Logística e Transporte para Produtos de Alto Valor Agregado no Contexto Brasileiro. Estudo não divulgado.

Effron, A. e Rose, J. (2002) Truck or train? A stated choice study on intermodalism in Argentina. Anais do XVII Congresso de Pesquisa e Ensino em Transporte, ANPET.

Ferguson, C.E. (1994) Microeconomia. Trad. Almir Guilherme Barbosa e Antônio Pessoa Brandão. 18 .ed. Rio de Janeiro: Forense Universitária.

Novaes, A. G. (1986) Sistemas de Transporte - Volume 1: Análise da Demanda. Edgard Blücher, São Paulo.

Ortúzar, J.D. e Willumsen, L.G. (1994), Modelling Transport. Chichester, England, 2a ed.

Senna, L. e Stanton (2002) Aplicação de QFD e Preferência Declarada no Transporte de Cabotagem. Transportes, v. XI, n. 1, junho de 2003. 